\title{
ON THE TEMPERATURE DEPENDENCE OF CREEP BEHAVIOR OF Ni-BASE SINGLE CRYSTAL SUPERALLOYS
}

\author{
P.Wollgramm ${ }^{1}, X . \mathrm{Wu}^{1}$, G.Eggeler $^{1}$ \\ ${ }^{1}$ Institut für Werkstoffe, Ruhr-Universität Bochum, 44801 Bochum, Germany
}

Keywords: Ni-base single crystal, creep, anisotropy, transmission electron microscopy

\begin{abstract}
In the present work we investigate the creep behavior of a single crystal superalloys (SX), using precisely oriented miniature tensile creep specimens. We study the single crystal superalloy ERBO/1 (CMSX-4 type) in the temperature range between 1023 and $1323 \mathrm{~K}$. We investigate how creep rates evolve in different stress/temperature regimes when tests are performed in the crystallographic loading directions [001], [110] and [111] and on how minimum creep rates depend on stress and temperature. Special emphasis is placed on the early stages of creep in the low temperature/high stress regime at $1023 \mathrm{~K}$ and $800 \mathrm{MPa}$.
\end{abstract}

\section{Introduction}

Ni-base single crystal superalloys (SX) are used for turbine blades which operate at temperatures between 850 and $1500 \mathrm{~K}$ [1-5]. Creep, the time dependent plastic deformation of materials, is one of the factors which limits service life of SX components. Materials processing, component design and gas turbine operation must ensure that the maximum potential of SX materials with respect to creep life can be exploited. This requires reliable uniaxial tensile creep data sets which document the shape of individual creep curves as well as the stress and temperature dependencies of creep rates. Creep is often simply represented by a power law of type

$$
\dot{\varepsilon}_{\min }=c \cdot \sigma^{\mathrm{n}} \cdot \exp \left(-Q_{\mathrm{app}} / R T\right)
$$

where $\dot{\varepsilon}_{\text {min }}$ is the secondary creep rate, $\sigma$ is the applied stress, $\mathrm{n}$ represents the stress exponent, $Q_{\text {app }}$ is the apparent activation energy and $R$ and $T$ have their usual meaning [6-10]. It is well

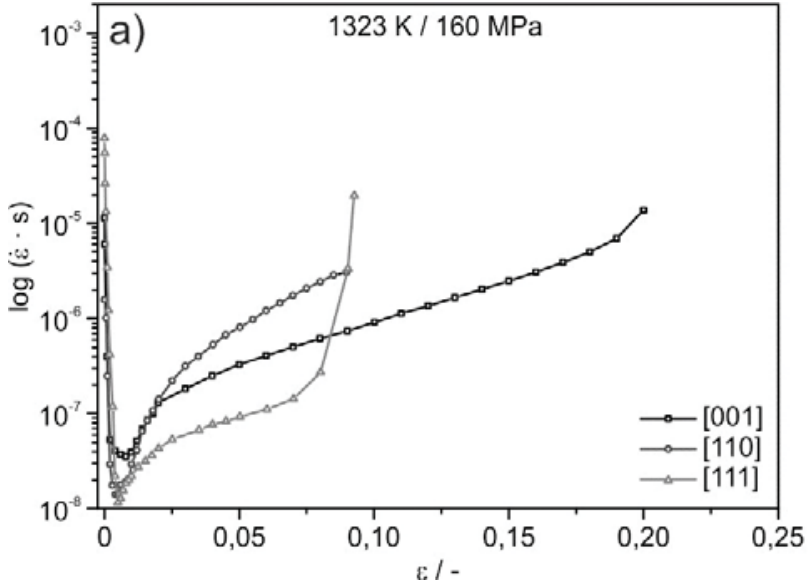

known that creep of SXs strongly depends on the two phase $\gamma / \gamma^{\prime}$-microstructure. The volume fraction and size of the $\gamma^{\prime}$-phase and microstructural parameters like $\gamma$-channel width play an important role $[4,5,9,11]$. In the present work we investigate the SX $\mathrm{ERBO} / 1$ (chemical composition equals CMSX-4). Its microstructure was carefully characterized on all length scales [12]. The present work has three objectives: to show how creep curve shapes change when different stress/temperature regimes and loading directions are considered, to investigate how the stress exponent $\mathrm{n}$ depends on the stress temperature regime, and finally, the present work provides an explanation for the double minimum type of [001] creep behavior which is observed for SXs at low temperatures and high stresses.

\section{Experiments}

For creep experiments, a miniature creep test technique was used which was previously described in the literature. It relies on an iterative procedure, which consists of orienting SX material in a Laue camera and EDM spark erosion machining of precisely oriented [001], [110] and [111] specimens (error $<1^{\circ}$ ). The specimens have a gauge lengths of $9 \mathrm{~mm}$ and rectangular cross section $\left(2 \times 3 \mathrm{~mm}^{2}\right)$. They are heated up to test temperature in a furnace with three independently controlled heating zones. Test temperatures were measured at the upper and lower end of the gauge lengths with two additional $\mathrm{Pt} 10 \mathrm{Rh} / \mathrm{Pt}$ thermocouples. Creep displacements were transferred by a ceramic rod in tube system to two linear vertical displacement transducers outside the furnace. The strain signal was obtained as the average of these two measurements. The specimens were heated under a preload corresponding to a stress of $20 \mathrm{MPa}$ and it took two/three hours to

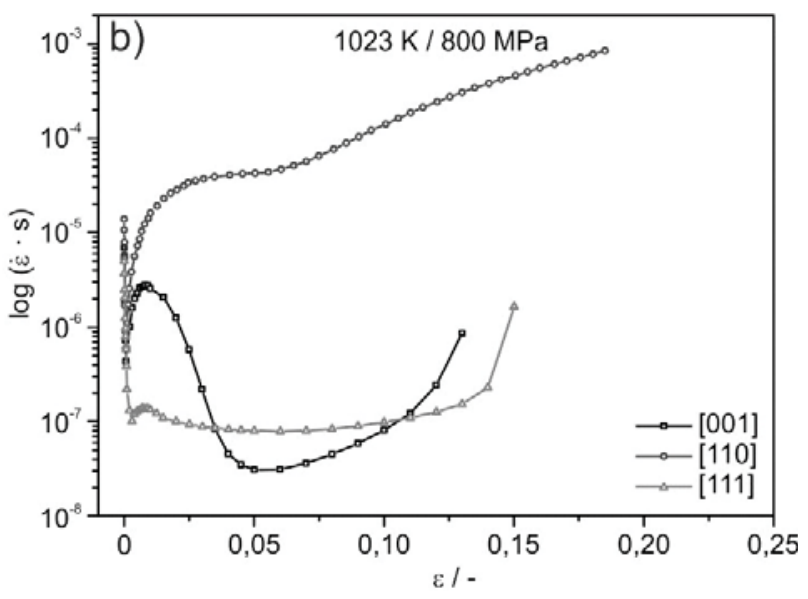

Figure 1. Creep curves for the three major crystallographic loading directions. (a) High temperature/low stress regime. (b) Low temperature/high stress regime. 


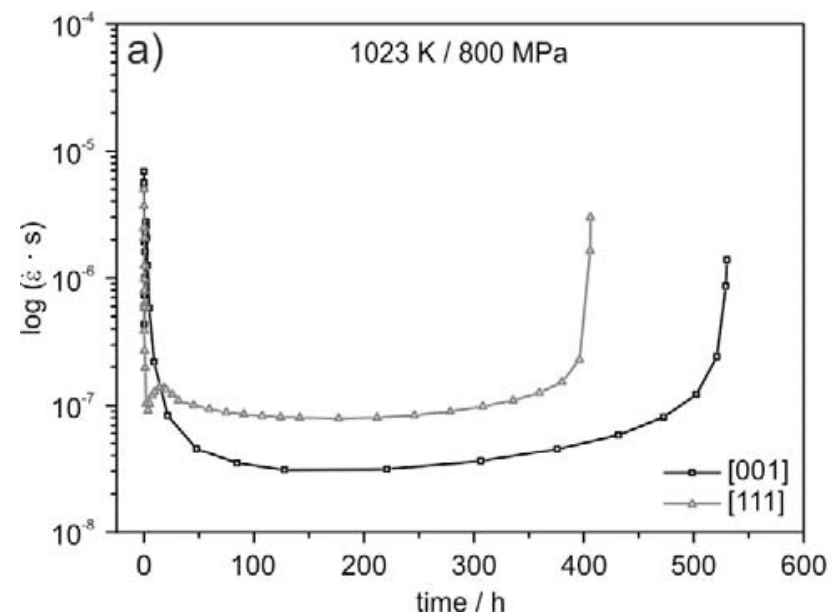

Figure 2. Low temperature/high stress creep curves of the [001] and [111] loading direction (a) logarithmic creep rate vs. time (b) logarithmic creep rate vs. logarithmic time.

reach a test temperature of $1023 / 1323 \mathrm{~K}$. Once the test temperature was reached, the total load was applied in a few seconds. Loading was followed by a period, where the lever arm is brought into a horizontal position. This automatic process took about one minute and once completed, constant load creep testing started. All other details of our creep test procedure have been described elsewhere [13-15].

We use transmission electron microscopy to document the evolution of microstructure during creep testing, with a special emphasis placed on $\gamma / \gamma^{\prime}$-morphologies and of defect structures (dislocations and planar faults). Interrupted creep tests were performed. Thin discs were cut from the gauge sections of the miniature specimens using a diamond saw. Thin foils were prepared by double jet thinning using an electrolyte of type A7, a voltage of approximately $13 \mathrm{~V}$ at a temperature of $270.5 \mathrm{~K}$. All details describing our TEM procedure have been published elsewhere [16-19].

\section{Results}

\section{$\underline{\text { Shapes of individual creep curves }}$}

As can be seen in Figure 1, the shapes of individual creep curves presented as log-linear-plots of creep rate vs. strain can differ considerably. They depend on the stress temperature/regime and on the loading direction. At high temperatures (1323 K) and low stresses $(160 \mathrm{MPa})$ different loading directions result in different creep curve shapes, Figure 1a. Most importantly, [110] and [111] loading directions are associated with smaller minimum creep rates, whereas the [001] loading direction shows the largest rupture strain. From an engineering point of view one may conclude, that the differences in the very early stages of creep, up to $2 \%$ creep strain, are not very pronounced. At low temperatures $(1023 \mathrm{~K})$ and high stress $(800 \mathrm{MPa})$ the effect of loading direction is much stronger. Especially the creep resistance in the [110] loading direction is poor with very high creep rates which are reached early on. For comparison, in Figure $1 \mathrm{~b}$ we present the low temperature high stress creep data in the same coordinate system as the high temperature data from Figure 1a. Subtle details cannot be resolved in Figure 1b. We therefore present the data from Figure 1b in two

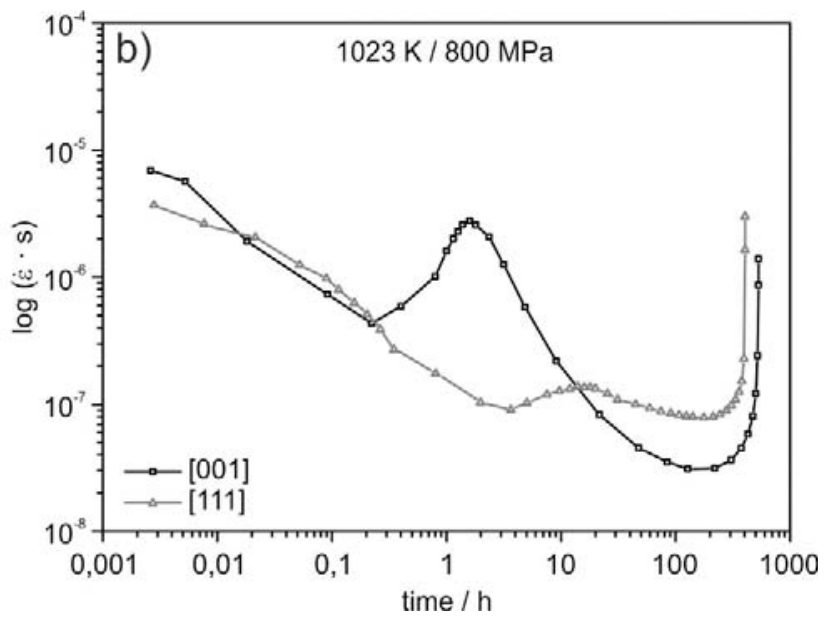

separate plots. Figure 2a shows the logarithmic creep rates of the [001] and [111] experiments as a function of time. It can be seen that most of the creep time is spent at the minimum or secondary creep rate. The [111] data show a small intermediate maximum in the early stages of creep which is observed after 15 hours. As can be seen in the log-log plot of creep rate vs. time in Figure 2b, the [001] creep experiment also shows a first creep rate minimum followed by an intermediate creep rate maximum before a global minimum is reached. It takes 30 minutes to reach the first sharp minimum while the global minimum is established after more than 100 hours. The peculiar behavior of the [001] creep curves is schematically illustrated in Figure 3, where shortly after loading, a first local minimum is observed (position 1 in Figure $3, \dot{\varepsilon}_{\text {local }}$ ). Thereafter, creep rates increase towards an intermediate local maximum (position 2 in Figure 3, $\dot{\varepsilon}_{\mathrm{im}}$ ) at an accumulated creep strain of $1 \%$. After the intermediate maximum, creep rates decrease towards a global creep rate minimum at a strain of $5 \%$ (position 3 in Figure $3, \dot{\varepsilon}_{\text {global }}$ ).

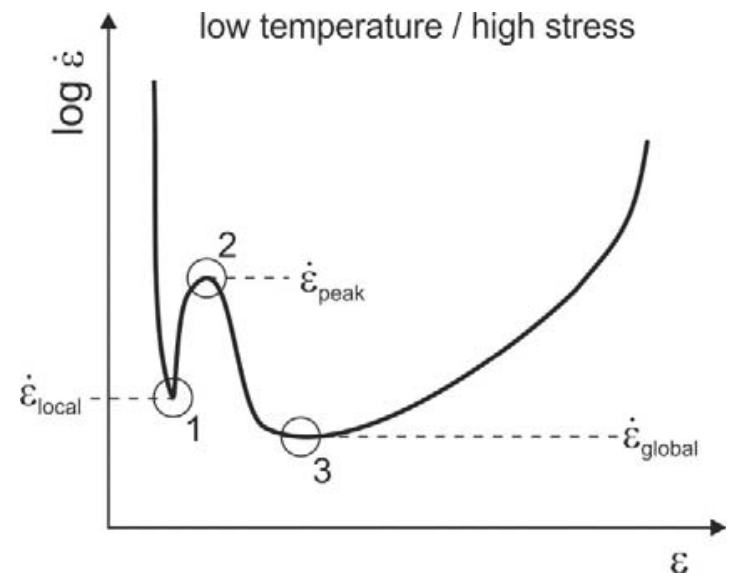

Figure 3. Schematic shape of a low temperature high and stress creep curve. At points 1-3 creep tests were interrupted for microstructural investigations.

This double minimum type of creep behavior is reproducible and has been reported previously [22, 23]. Interrupted creep tests for 
different strains were performed to study this phenomenon and to explain the behavior shown in Figure 3.

Stress dependence of minimum creep rates:

In the present work stress exponents $\mathrm{n}$ and apparent activation energies $Q_{\text {app }}$ from Equation 1 were determined. In Figure 4 we present creep data which were obtained in the stress temperature regime close to $1223 \mathrm{~K}$ and $300 \mathrm{MPa}$. Six creep tests were performed at three stress levels $(270,300$ and $330 \mathrm{MPa}$ at $1223 \mathrm{~K})$ and three temperatures (1193, 1223 and $1253 \mathrm{~K}$ at $300 \mathrm{MPa})$. Two tests were conducted at the intermediate stress/temperature condition $(1223 \mathrm{~K}, 300 \mathrm{MPa})$. In Figure 4a the position of one minimum creep rate (for the $270 \mathrm{MPa}$ experiment) is indicated as an example. Figures $4 \mathrm{a}$ and $\mathrm{c}$ consider the stress dependence of the minimum creep rate in this creep regime. Figure $4 \mathrm{a}$ shows four creep curves, the logarithm of creep rate is plotted as a function of time. The two tests which were performed at the same intermediate stress level do not yield exactly the same minimum creep rates. Instead, these two tests yield minimum creep rates which differ by a little more than 10\%. In Figure $4 \mathrm{c}$ we present the corresponding
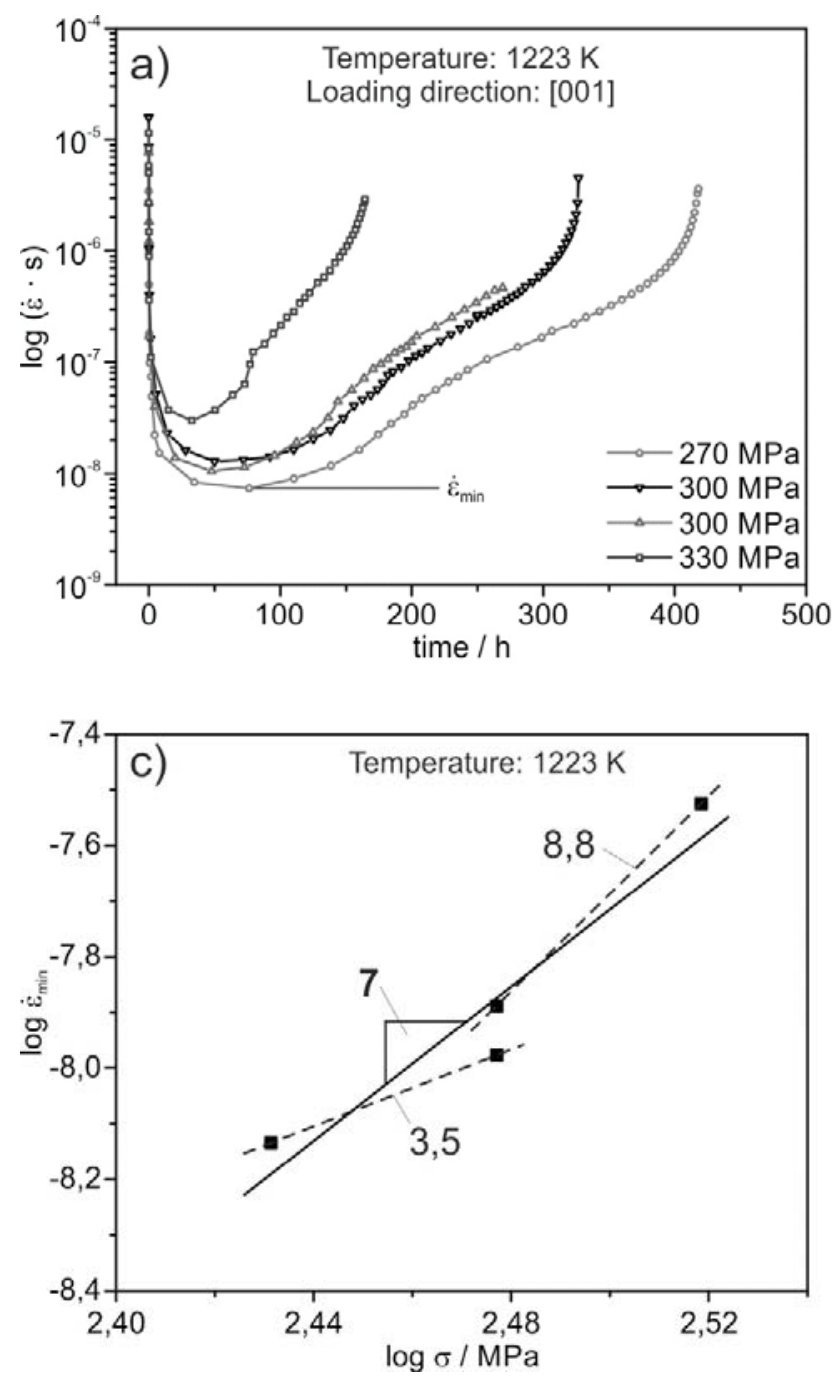

Norton diagram, where minimum creep rates are plotted as a function of stress in a log-log plot. Using a linear regression analysis, a Norton stress exponent of 7 is obtained considering all four data points. In order to obtain a feel for the scatter of the stress exponent $\mathrm{n}$, we draw two additional dashed lines in Figure 4c, each connecting only two (out of four) data points. The slope of the first line yields a stress exponent of 3.5 while the slope of the second line corresponds to a stress exponent of 8.8. Obviously, evaluating $\mathrm{n}$ from four experiments and considering a larger stress range yields more reliable data. However, the results presented in Figure 4c suggest that $n$-values are associated with scatter, which can be larger than \pm 1 .

In Figure $4 \mathrm{~b}$ we show four creep tests, which were performed at different temperatures. The corresponding Arrhenius plot, where the natural logarithm of the minimum creep rates is plotted as a function of the inverse temperature, is shown in Figure 4d. Considering all four data points, a linear regression analysis yields an apparent activation energy of creep of $516 \mathrm{~kJ} / \mathrm{mol}$. In order to obtain a feel for the scatter in Qapp-values, we apply the same procedure as in Figure 4c. Two resulting dashed lines which each
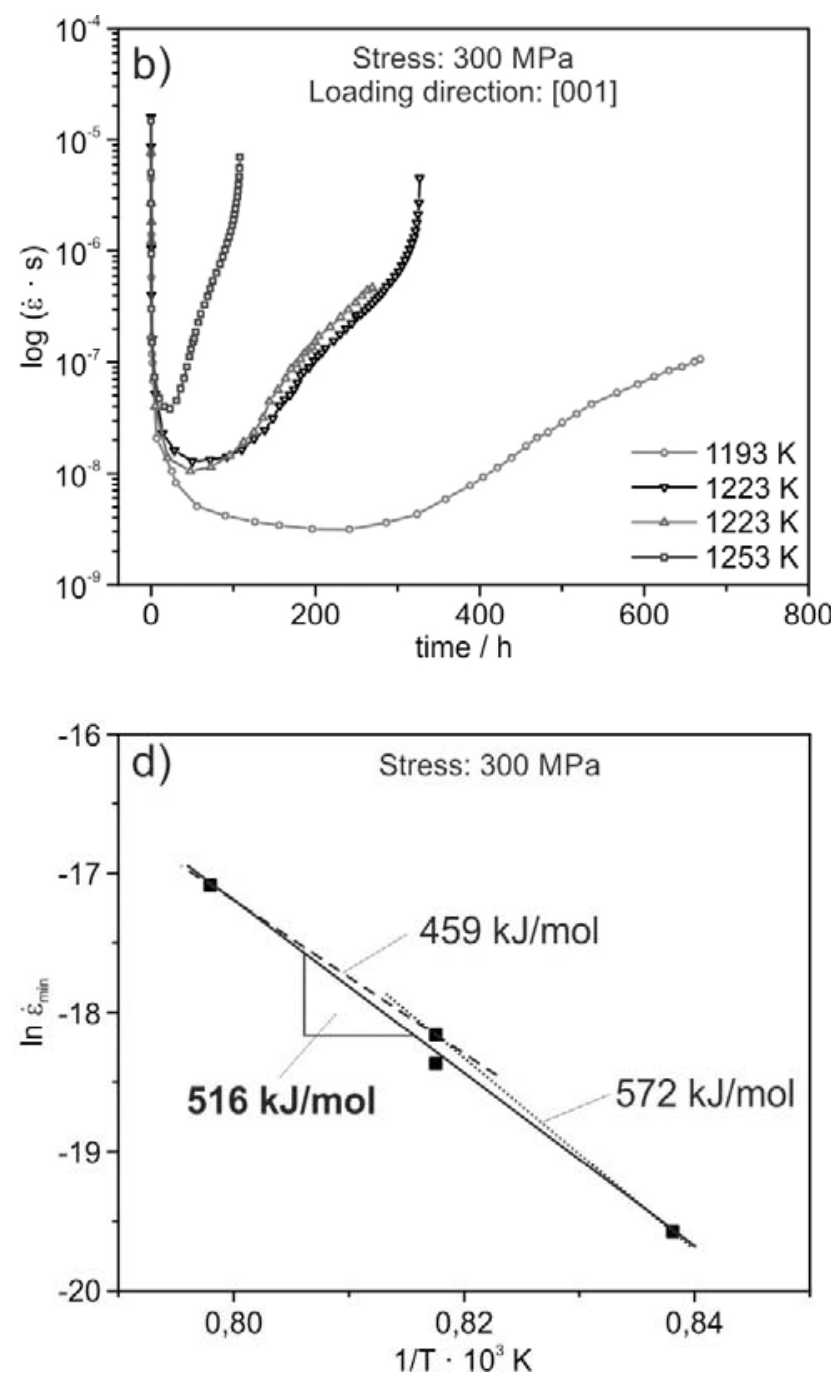

Figure 4. Creep data from the $1223 \mathrm{~K}$ and $300 \mathrm{MPa}$ regime. (a) Log linear plots of creep rate vs. strain at $1223 \mathrm{~K}$ and 270,300 and $330 \mathrm{MPa}$. (b) Log linear plots of creep rate at $300 \mathrm{MPa}$ and 1193, 1223 and $1253 \mathrm{~K}$. (c) Minimum creep rate data from a) in a Norton plot. (d) Minimum creep data from b) presented in an Arrhenius diagram. 
connect two data points yield apparent activation energies of $459 \mathrm{~kJ} / \mathrm{mol}$ and $572 \mathrm{~kJ} / \mathrm{mol}$. This suggests, that apparent activation energies can have errors which are of the order of $\pm 50 \mathrm{~kJ} / \mathrm{mol}$.

Minimum creep rates from narrow stress/temperature regimes can always be rationalized by Equation 1 (data fall on straight lines in Norton and Arrhenius plots). This holds for the minimum creep rates $\dot{\varepsilon}_{\text {min }}$ from the intermediate (1123 and $\left.1223 \mathrm{~K}\right)$ and high $(1323 \mathrm{~K})$ temperature regimes. This also holds for the three characteristic creep rates $\left(\dot{\varepsilon}_{\text {local }}, \dot{\varepsilon}_{\text {im }}\right.$ and $\left.\dot{\varepsilon}_{\text {global }}\right)$ which characterize the low temperature high stress regime, Figure 3. The stresses considered in the test program were always significantly smaller than those which are typically associated with constant strain rate tensile testing and creep rates always increased with increasing temperature (no mechanisms which lead to yield stress anomaly need to be discussed). In Figure 5 we plot the results which were obtained from the $<001>$ tensile creep tests. Four specific stresstemperature regimes were considered limited by a low temperature high stress $(1023 \mathrm{~K} \pm 30 \mathrm{~K} / 800 \pm 50 \mathrm{MPa})$ and a high temperature low stress $(1323 \mathrm{~K} \pm 30 \mathrm{~K} / 160 \pm 20 \mathrm{MPa})$ regime.
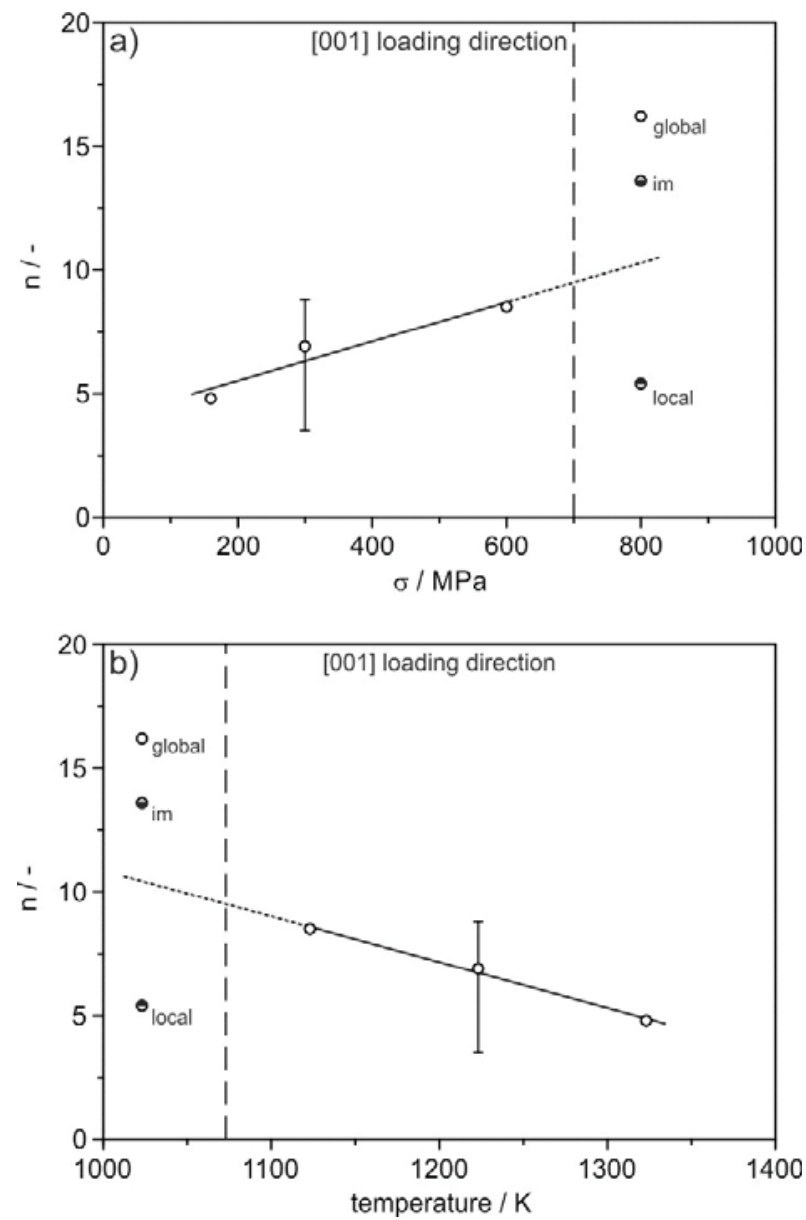

Figure 5. Stress and temperature dependencies of minimum creep rates $\dot{\varepsilon}_{\min }(\mathrm{T}>1073 \mathrm{~K}, \sigma<700 \mathrm{MPa})$ and characteristic creep rates $\dot{\varepsilon}_{\text {local }}, \dot{\varepsilon}_{\text {im }}$ and $\dot{\varepsilon}_{\text {global }} \quad(\mathrm{T}=1023 \mathrm{~K}, \sigma=800 \mathrm{MPa})$ obtained from [001] creep data. (a) Stress dependence of stress exponent $n$. (b) Temperature dependence of stress exponent n. Error bars see Figure 4c.
Figure 5 shows how the stress exponents $\mathrm{n}$ depend on stress and temperature. Figures $5 \mathrm{a}$ and $\mathrm{b}$ show that $\mathrm{n}$-values increase with increasing stress and decrease with increasing temperature. Especially the $\mathrm{n}$ values at low temperature and high stress, determined for the three characteristic regions, differ considerably.
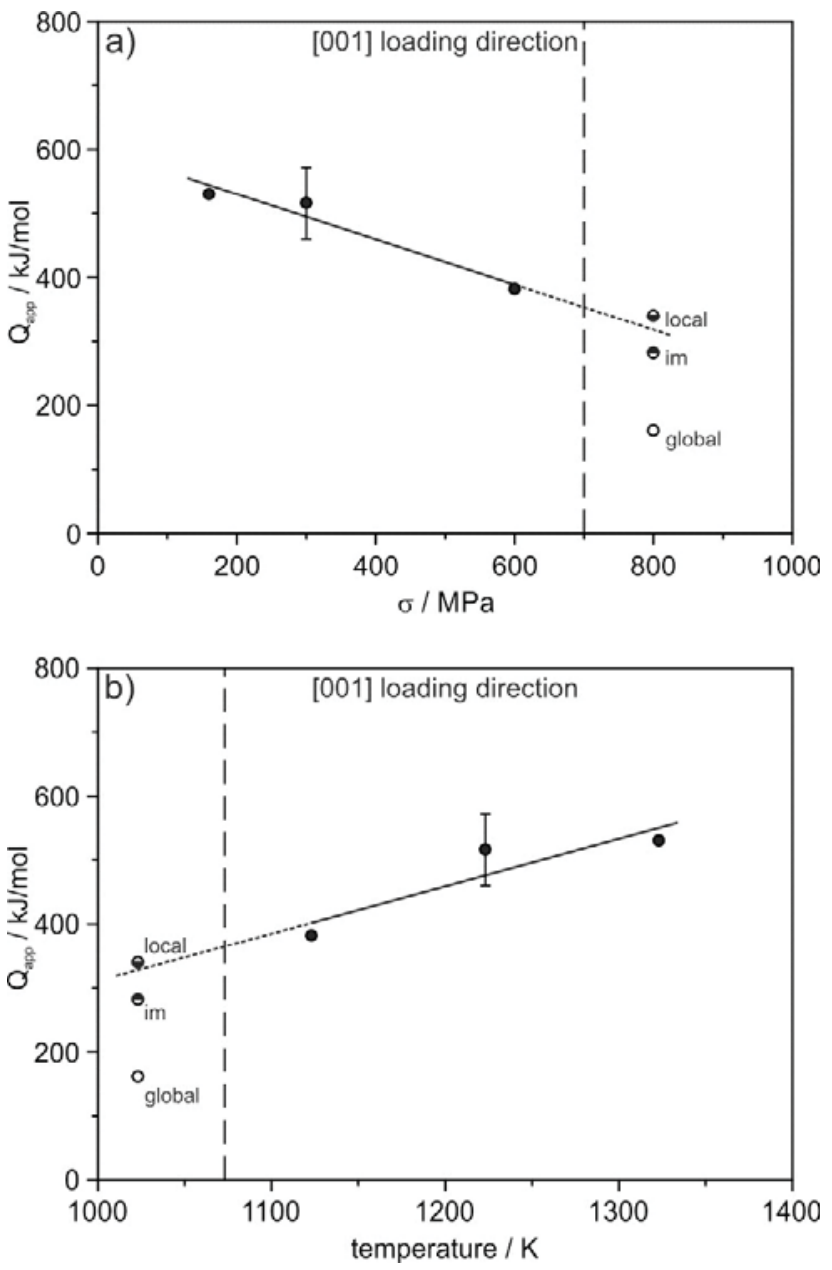

Figure 6. Stress and temperature dependencies of minimum creep rates $\dot{\varepsilon}_{\min }(\mathrm{T}>1073 \mathrm{~K}, \sigma<700 \mathrm{MPa})$ and characteristic creep rates $\dot{\varepsilon}_{\text {local }}, \dot{\varepsilon}_{\text {im }}$ and $\dot{\varepsilon}_{\text {global }} \quad(\mathrm{T}=1023 \mathrm{~K}, \sigma=800 \mathrm{MPa})$ obtained from [001] creep data. (a) Stress dependence of apparent activation energy $Q_{\text {app. }}$ (b) Temperature dependence of apparent activation energy $Q_{\text {app }}$. Error bars see Figure $4 \mathrm{~d}$.

Apparent activation energies $Q_{\text {app }}$ show the opposite behavior. They decrease with increasing stress and increase with increasing temperature, Figure $6 a$ and b. Figure 5 and 6 also show that the high and intermediate temperature data can be rationalized by common lines for temperatures between 1123 and $1323 \mathrm{~K}$. The data from the low temperature high stress regime do not fall on these trend lines. Most importantly, the global minima of the [001] tests are always far off.

In Figures 7a and $b$ we use the trend lines of the [001] data from Figure 5 as reference (dotted lines). We keep in mind that these trend lines only fit the creep results of the experiments which were performed at the three highest test temperatures respectively at the three lowest stresses. The trend lines do not represent the [001] low 
temperature/high stress data $(1023 \mathrm{~K} / 800 \mathrm{MPa})$. When looking at these trend lines it must also be kept in mind, that it is not possible to perform creep experiments at 1023 and $1323 \mathrm{~K}$ at the same stress level. When $160 \mathrm{MPa}$ are applied at $1023 \mathrm{~K}$, one can hardly observe any creep strain accumulation. When $800 \mathrm{MPa}$ are applied at $1323 \mathrm{~K}$, on the other hand, specimens would fail immediately. In the present work we have probed stress and temperature dependencies in meaningful stress and temperature windows. The trend lines shown in Figures 5 to 7 show how the resulting n- and Q-values change and are useful when comparing the [001] results to the findings for the other two loading directions.
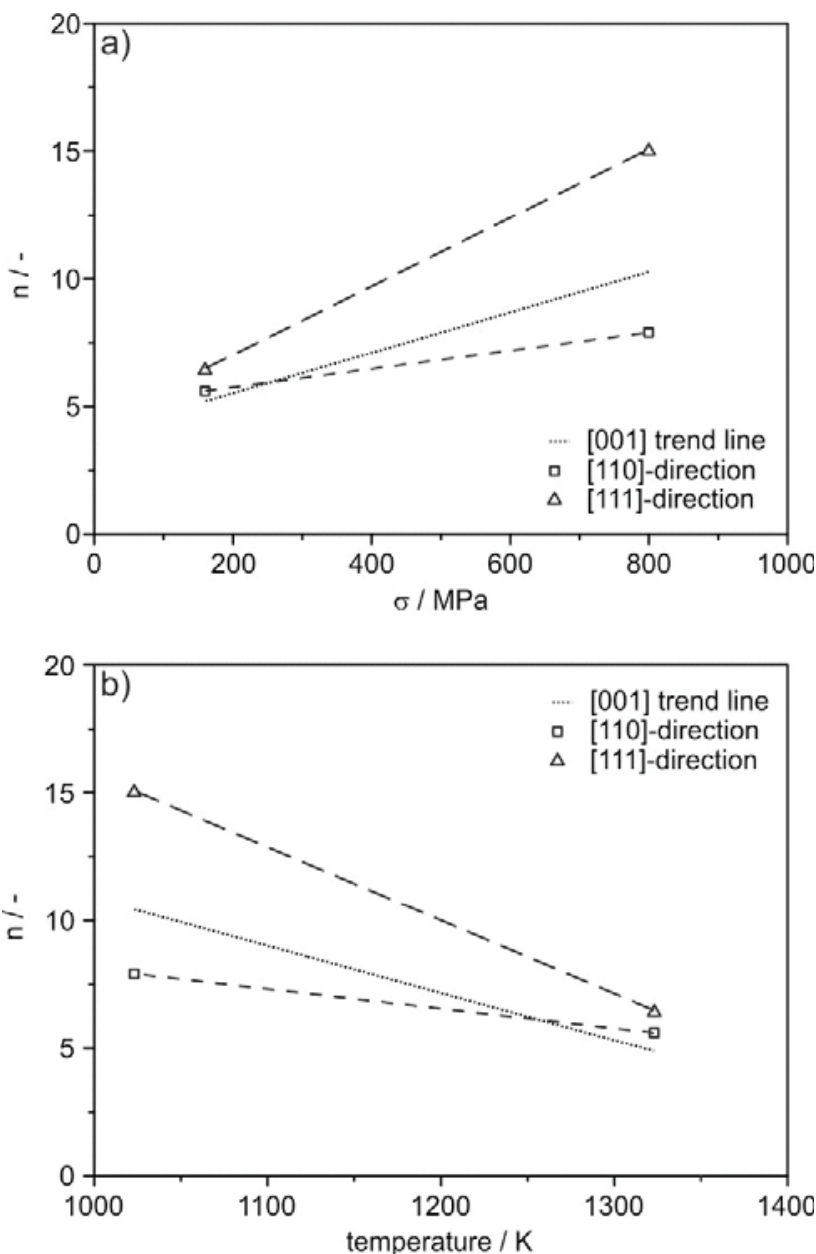

Figure 7. Stress and temperature dependencies of minimum creep rates $\dot{\varepsilon}_{\min }(\mathrm{T}=1323 \mathrm{~K}, \sigma=160 \mathrm{MPa})$ and characteristic creep rates $\dot{\varepsilon}_{\text {local }}(\mathrm{T}=1023 \mathrm{~K}, \sigma=800 \mathrm{MPa})$ obtained from [110] and [111] creep data. (a) Stress dependence of stress exponent n. (b) Temperature dependence of stress exponent $n$.

Figure 7a shows that the [110] and [111] minimum creep rates from the high temperature/low stress creep regime $(160 \mathrm{MPa})$ fall close to the [001] trend line and also increase with increasing stresses. However, the low temperature/high stress local minimum creep rate data deviate considerably. The [111] stress exponent shows a stronger stress dependence than the stress exponents determined for $[001]$ and $[110]$ tests. Figure $7 \mathrm{~b}$ shows the temperature dependence of the stress exponent $n$. The [110] and [111] n-values from the high temperature low stress regime do not strongly differ from the [001] data, while the low temperature values scatter between $n=7.5$ and $\mathrm{n}=15$.

In contrast to the determined n-values, the apparent activation energies $Q_{\text {app }}$ for [110] and [111] tensile testing do not follow the trend of the [001]-data (not shown here, for further information see [15]). The values of $Q_{\mathrm{app}}$ for [110] as well as [111] tensile testing remain on a constant level of $350 \mathrm{~kJ} / \mathrm{mol}$ and $570 \mathrm{~kJ} / \mathrm{mol}$ and do not increase with increasing temperature or with decreasing stress.

\section{Microstructural evolution:}

In Figures $8 \mathrm{a}$ to $\mathrm{c}$ we show three TEM micrographs from microstructures observed at positions 1,2 and 3 of the low temperature/high stress creep curve shown in Figure 3. The micrographs were obtained from $\{111\}$ cross sections which were cut out after [001] tensile creep.

At the first local minimum (position 1), we mainly observe dislocation activity in the $\gamma$-channels, Figure 6a. The intermediate creep rate maximum (position 2 in Figure 3 ) is characterized by the presence of $\gamma$-channel dislocations and planar faults in the $\gamma$ 'particles which show no sign of rafting in the low temperature/high stress creep regime, Figure $8 \mathrm{~b}$. After $5 \%$ creep strain, at the position of the global minimum (position 3 in Figure 3), we observe a high dislocation density in the $\gamma$-channels. Dislocations have also entered the $\gamma^{\prime}$-phase particles, Figure 8c.

\section{Discussion}

The results presented in the present work show that the features of individual creep curves depend on the stress/temperature regime and on the crystallographic loading direction. This is in line with results reported earlier [20,21]. Equation 1 can only rationalize experimental data when limited stress/temperature ranges are considered. For [001] tensile tests it is observed, that stress exponents $\mathrm{n}$ increase with stress and decrease with temperature. In contrast, apparent activation energies $Q_{\text {app }}$ decrease with increasing stress and increase with temperature. These results suggest that creep of complex SX cannot simply be rationalized by natural creep laws or on the basis of specific thermally activated events. The results obtained in the present work also confirm the double minimum type of creep behavior which was reported for CMSX-4 in the low temperature and high stress [001] tensile creep regime $[22,23]$. The early decrease in creep rate towards the first minimum did not receive much attention in the literature. In contrast, the subsequent increase of creep rate up to the intermediate creep rate maximum was reported in several studies [21-28]. Why creep rates evolve in this way is still an open question. Our preliminary TEM results presented in Figure 8 suggest that the early decrease of creep rate to the first local minimum is related to dislocation processes in the $\gamma^{\prime}$-channels, Figure 8a. The increase towards the intermediate creep maximum is associated with shearing of the $\gamma^{\prime}$-phase by stacking fault ribbons, as described in the literature $[4,19]$, Figure $8 \mathrm{~b}$. The decrease towards the global minimum at 5\% strain is associated with strain hardening, i.e. an increase of dislocation density in the $\gamma$-channels and in the $\gamma$ '-phase, Figure 8c.

Two previous publications have addressed the temperature dependence of the apparent activation energy of creep [29,30]. 

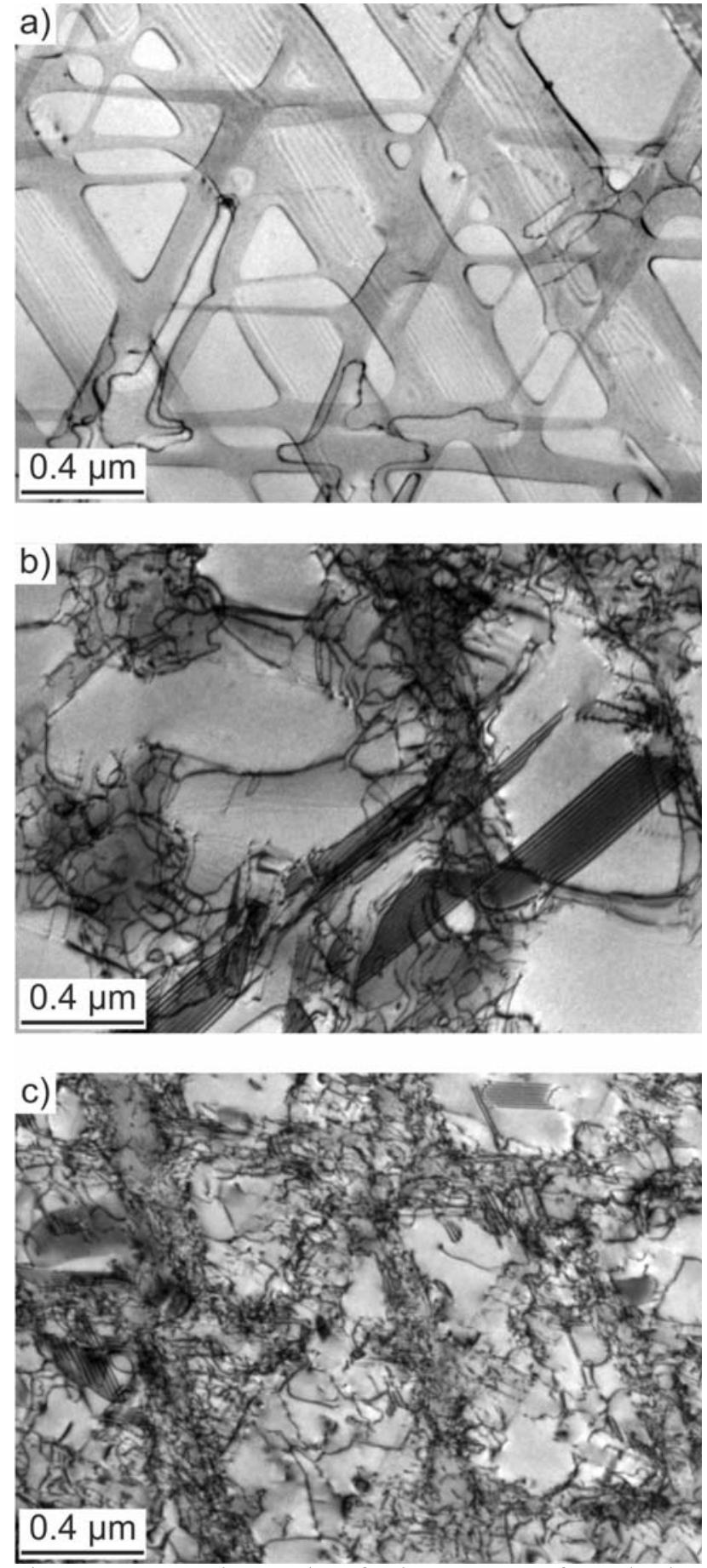

Figure 8. TEM micrographs of microstructures from the low temperature and high stress regime. (a) Mainly dislocation activity in the $\gamma$-channels. (b) Increased dislocation density in the $\gamma$ channels, planar faults in the $\gamma^{\prime}$-particles. (c) High $\gamma$-channel dislocation density. Dislocations have entered the $\gamma^{\prime}$-phase.

They both report a change from high activation energies at high temperatures/low stresses to low activation energies at low temperatures/high stresses. Leverant et al. [29] reported for MarM200 single crystals, that there is an activation energy of $255 \mathrm{~kJ} / \mathrm{mol}$ for primary creep at $1033 \mathrm{~K}$, while they find $615 \mathrm{~kJ} / \mathrm{mol}$ for secondary creep at $1130 \mathrm{~K}$. Drew et al. [30] reported for CMSX4 tested at stresses of 650 and $750 \mathrm{MPa}$ in the 1023 to $1123 \mathrm{~K}$ temperature range apparent activation energies of 230 and $296 \mathrm{~kJ} / \mathrm{mol}$. Decreasing the stress to $550 \mathrm{MPa}$, where planar faults are no longer observed, they find $546 \mathrm{~kJ} / \mathrm{mol}$. Our data presented in Figures $6 \mathrm{a}$ and $\mathrm{b}$ suggest that the results for primary creep reported in $[29,30]$ correspond to our $\dot{\varepsilon}_{\text {im }}$-data. These low values are associated with the $\gamma^{\prime}$-cutting by planar faults. For the high temperature and low stress regimes literature results $[29,30]$ and the results of the present study yield $Q_{\text {app }}$ values $>500 \mathrm{~kJ} / \mathrm{mol}$. Both previous works $[29,30]$ suggest that there is no continuous change in activation energies as suggested by the plots shown in Figures 6a and $b$, but that there is a high value which they associate with the deformation of the $\gamma$-channels (high temperature/low stress mechanism) and a low value which is related to $\gamma$ ' shear by stacking faults (low temperature/high stress mechanism). We interpret our findings in terms of a scenario, where at higher temperatures, where no stacking faults are observed, there is a gradual decrease of activation energies with decreasing temperature due to a gradual decrease of the intensity of rafting. We also believe that the higher intensity of rafting during [001] tensile creep testing is responsible for the higher temperature dependence of the activation energies as compared to the activation energies observed in [110] and [111] creep testing, where rafting is less pronounced. Further work is required to clarify these points.

\section{Summary and Conclusion}

In the present work we report creep results which were obtained for the Ni-base single crystal superalloy ERBO/1 (CMSX-4 type) using a miniature creep test technique. Precisely oriented [001], [110] and [111] specimens were considered (angular deviation: $\pm 1^{\circ}$ ). From the results obtained in the present work, the following conclusions can be drawn:

(1) The shape of individual creep curves depends on the stress/temperature regime and on the crystallographic loading direction.

(2) Equations which describe creep by a power law stress dependence and an Arrhenius type of temperature dependence only work in limited stress temperature regimes.

(3) For all tensile loading directions, one observes an increase of the stress exponent $\mathrm{n}$ with stress and a decrease of $\mathrm{n}$ with temperature.

(4) For [001] tensile loading, apparent activation energies of creep decrease with increasing stress and decrease with increasing temperature. This clear stress and temperature dependence of $Q_{\text {app }}$ is not observed during [110] and [111] tensile testing. Further work is required to investigate this phenomenon.

(5) The double minimum creep behavior observed during low temperature high stress [001] tensile testing is related to three processes. Dislocation processes in the $\gamma$-channels which lead to a decrease of creep rate until a first local minimum is reached. $\gamma^{\prime}$-cutting processes which rely on stacking fault ribbons account for an increase of creep rate up to an intermediate maximum. And finally, during strain hardening in both phases, creep rates decrease until they reach a global minimum. Further work is required to quantitatively explain the evolution of creep rate during low temperature and high stress creep. 


\section{Acknowledgement}

The authors acknowledge funding by the Deutsche Forschungsgemeinschaft through projects A1 and A2 of the collaborative research center SFB/TR 103 (see: www.sfbtransregio103.de).

\section{References}

1. G.W. Meetham, The Development of Gas Turbine Materials (London, Applied Science Publishers, 1981).

2. M. McLean, Directionally Solidified Materials for High Temperature Service (London, The Metal Society, 1983).

3. M. Durand-Charre, (The Microstructure of Superalloys, CRC Press, 1997).

4. T.M. Pollock and R.D. Field, Dislocations and HighTemperature Plastic Deformation of Superalloy Single Crystals, in: F.R.N. Nabarro and M.S. Duesbery (Eds.), Dislocations in Solids, Elsevier Sciences, 2002, 566-568.

5. R.C. Reed, The Superalloys: Fundamentals and Applications (Cambridge, Cambridge University Press, 2006).

6. B. Ilschner, Hochtemperatur-Plastizität (Berlin, Springer Verlag, 1973).

7. J.P. Poirier, Creep of Crystals: High-temperature Deformation Processes in Metals, Ceramics and Minerals (Cambridge, Cambridge University Press, 1985).

8. R.W. Evans and B. Wilshire, Creep of Metals and Alloys (London, Institute of Materials, 1985).

9. F.R.N. Nabarro and F. De Villiers, The Physics of Creep (London, Taylor and Francis, 1995).

10. J. Cadek, Creep in metallic materials (Amsterdam, Elsevier, 1988).

11. P. Caron, Y. Ohta, Y.G. Nakagawa and T. Khan, "Creep deformation anisotropy in single crystal superalloys", in: S. Reichmann et al. (Eds.), Superalloys 1988, The Metallurgical Society, TMS, 1988, 215-224.

12. A.B. Parsa, P. Wollgramm, H. Buck, C. Somsen, A. Kostka, I. Povstugar, P.P. Choi, D. Raabe, A. Dlouhy, J. Müller, E. Spiecker, K. Demtroeder, J. Schreuer, K. Neuking and G. Eggeler, "Advanced Scale Bridging Microstructure Analysis of Single Crystal Ni-Base Superalloys", Adv. Eng. Mater., 17 (2015), 216230.

13. G. Maelzer, R.W. Hayes, T. Mack and G. Eggeler, "Miniature specimen assessment of creep of the single-crystal superalloy LEK 94 in the 1000 degrees C temperature range", Metall. Mater. Trans. A, 38 (2007), 314-327.

14. P. Wollgramm, H. Buck, K. Neuking, A. Parsa, S. Schuwalow, J. Rogal, R. Drautz and G. Eggeler, "On the role of Re in the stress and temperature dependence of creep of Ni-base single crystal superalloys", Mat. Sci. Eng. A-Struct., 628 (2015), 382-395.

15. P. Wollgramm, D. Bürger, A. B. Parsa, K. Neuking and G. Eggeler, "The Effect of Stress, Temperature and Loading Direction on the Creep Behavior of Ni-base Single Crystal Superalloy Miniature Tensile Specimens", submitted to Materials at High Temperatures, 2016.

16. X. Wu, P. Wollgramm, C. Somsen, A. Dlouhy, A. Kostka and G. Eggeler, "Elementary deformation processes in the early stages of low temperature / high stress creep of single crystal Ni-base super alloys", accepted for publication in Acta Mater., 2016.

17. L. Agudo Jácome, P. Nörtershäuser, J.-K. Heyer, A. Lahni, J. Frenzel, A. Dlouhy, C. Somsen and G. Eggeler, "High-temperature low-stress creep anisotropy of single-crystal superalloys", Acta Mater., 61 (2013) 2926-2943.

18. L. Agudo Jácome, P. Nörtershäuser, C. Somsen, A. Dlouhy and G. Eggeler, "On the nature of $\gamma$-phase cutting and its effect on high temperature and low stress creep anisotropy of Ni-base single crystal superalloys", Acta Mater., 69 (2014) 246-264.

19. P. Nörtershäuser, J. Frenzel, A. Ludwig, K. Neuking and G. Eggeler: "The effect of cast microstructure and crystallography on rafting, dislocation plasticity and creep anisotropy of single crystal Ni-base superalloys", Mat. Sci. Eng. A-Struct., 626 (2015), 305312 .

20. T.M. Pollock and A.S. Argon, "Creep resistance of CMSX-3 nickel-base superalloy single-crystals", Acta Metall. Mater., 41 (1993), 2253-2253.

21. C.M.F. Rae and R.C. Reed, "Primary creep in single crystal superalloys: Origins, mechanisms and effects", Acta Mater., 55 (2007), 1067-1081.

22. W. Schneider, H. Mughrabi and J. Hammer, "Creep Deformation and Rupture Behaviour of the Mono Crystalline Superalloy CMSX-4 - A Comparison with the Alloy SRR 99", in: S.D. Antolovich et al. (Eds.), Superalloys 1992, TMS, Warrendale, 1992, 589-598.

23. V. Sass, W. Schneider and H. Mughrabi, "On the orientation dependence of the intermediate-temperature creep behaviour of a monocrystalline nickel-base superalloy", Scripta Metall. Mater. 31 (1994) 885-890.

24. V. Sass, U. Glatzel and M. Feller-Kniepmeier, "Anisotropic creep properties of the Nickel-base superalloy CMSX-4", Acta Mater. 44 (1996) 1967-1977.

25. N. Matan, D.C. Cox, P. Carter, M.A. Rist, C.M.F. Rae and R.C. Reed, "Creep of CMSX-4 superalloy single crystals: effects of misorientation and temperature", Acta Mater. 47 (1999) 15491563.

26. J. Svoboda and P. Lukas, "Model of creep in $<001>$-oriented superalloy single crystals", Acta Mater. 46 (1998) 3421-3431. 
27. C.M.F. Rae, N. Matan, D.C. Cox, M.A. Rist and R.C. Reed, "On the primary creep of CMSX-4 superalloy single crystals", Metall. Trans. A, 31 (2000) 2219-2228.

28. C.M.F. Rae, N. Matan and R. Reed, "The role of stacking fault shear in the primary creep of [001]-oriented single crystal superalloys at $750^{\circ} \mathrm{C}$ and $750 \mathrm{MPa} "$, Mater. Sci. Eng. A 300 (2001) 125-134.

29. G.R. Leverant, B.H. Kear and J.M. Oblak, "Creep of precipitation-hardened Nickel-base alloy single crystals at high temperatures”, Metall. Trans, 4 (1973), 355-362.

30. G.L. Drew, R.C. Reed, K. Kakehi and C.M.F. Rae, "Single crystal superalloys: The transition from primary to secondary creep", in: K.A. Green et al. (Eds.), Superalloys 2004, The Metallurgical Society, TMS, 2004, 127-136. 